\title{
Измерение времени жизни колебательных состояний молекул ДНК в функционализированных комплексах полупроводниковых квантовых точек
}

\author{
(C) Ф.Б. Байрамов ${ }^{1,2}$, Е.Д. Полоскин ${ }^{2}$, А.Л. Чернев ${ }^{1}$, В.В. Топоров ${ }^{2}$, \\ М.В. Дубина ${ }^{1}$, Б.Х. Байрамов ${ }^{2}$ \\ ${ }^{1}$ Санкт-Петербургский академический университет - \\ научно-образовательный центр нанотехнологий Российской академии наук, \\ 194021 Санкт-Петербург, Россия \\ ${ }^{2}$ Физико-технический институт им. А.Ф. Иофрфе РАН, \\ 194021 Санкт-Петербург, Россия \\ E-mail: bairamov@mail.ioffe.ru
}

(Получена 21 марта 2017 г. Принята к печати 4 апреля 2017 г.)

Комплексы самоорганизованных изолированных полупроводниковых кристаллических квантовых точек $n c-\mathrm{Si} / \mathrm{SiO}_{2}$, функционализированных короткими олигонуклеотидами, являются уникальными объектами для выявления особенностей проявления новых квантово-размерных эффектов. Показано, что обнаружение узких спектральных линий в спектрах микрорамановского рассеяния света высокого спектрального разрешения позволяет определить характерный масштаб времен колебательных возбуждений молекул нуклеотидов. Установлена возможность количественного изучения структурно-динамических свойств быстропротекающих колебательных процессов в биомакромолекулах.

DOI: 10.21883 /FTP.2017.10.45016.8583

\section{1. Введение}

Развитие новых направлений нанобиофотоники и наномедицины предъявляют повышенный интерес к созданию и исследованиям нового класса низкоразмерных наноструктур - нанобиогибридных комплексов полупроводниковых квантовых точек, функционализированных молекулами нуклеиновых кислот. Такие структуры имеют большое значение для наноконструирования самых разных гибридных устройств. Особое внимание к этому классу материалов также связано с важным значением в нашей жизни и самих биомакромолекул, и, в частности, олигонуклеотидов, являющихся фрагментами дезоксирибонуклеиновых (ДНК) или рибонуклеиновых (РНК) кислот. Вследствие этого изучение механизмов взаимодействия между отдельными атомами, молекулами и функциональными группами самих олигонуклеотидов, а также зависимости этих механизмов от физико-химических свойств окружающей среды представляются весьма значимыми. Специальный интерес вызывают ранее не изученные, молекулярные механизмы ковалентного связывания отдельных молекул ДНК с неорганическими полупроводниковыми наноструктурами. В первую очередь это обусловлено уникальными флуоресцентными свойствами полупроводниковых квантовых точек. Все это позволяет создавать эффективные аналитические и биомедицинские диагностические методики, средства адресной доставки лекарственных препаратов к клеткаммишеням.

Без фундаментальных структурных исследований и детального понимания физических процессов, протекающих как в отдельности в исходных системах - полупроводниковых квантовых точках и белковых молекулах, ДНК, так и в целостной функционализированной структуре $[1-21]$, невозможно успешное развитие вышеуказанных направлений нанотехнологий. При этом одной их актуальных задач является необходимость совершенствования и разработки новых эффективных методов исследования на молекулярном уровне. Одним из эффективных аналитических методов исследования структуры таких сложных систем на молекулярном уровне является спектроскопия неупругого рассеяния света. Полупроводниковые квантовые точки $n c-\mathrm{Si} / \mathrm{SiO}_{2}$, благодаря уникальным физическим и химическим свойствам, в частности высокому квантовому выходу и возможности перестройки длины волны фотолюминесценции в широком спектральном видимом диапазоне спектра [2-13], а также биосовместимых для организма человека, представляют большой интерес.

В данной работе приводятся результаты исследования функционализации полупроводниковых квантовых точек $n c-\mathrm{Si} / \mathrm{SiO}_{2}$ наноструктур одноцепочными короткими олигонуклеотидами на примере системы $d(20 \mathrm{G}, 20 \mathrm{~T})$. Здесь $d$ - дезоксирибонуклеотиды, $\mathrm{G}$ и $\mathrm{T}$ - нуклеотиды гуанин и тимин соответственно. Экспериментальные исследования выполнены с помощью развитой методики спектроскопии микрорамановского рассеяния света высокого спектрального и пространственного разрешений, а также высокой чувствительности регистрации спектров. Они позволили обнаружить сложные спектры таких комплексов и, что особенно важно, выявить узкие спектральные линии, соответствующие отдельным молекулам олигонуклеотидов. Показано, что обнаружение узких спектральных линий в спектрах неупругого рассеяния света высокого спектрального разрешения 
позволяет определить характерный масштаб времен колебательных возбуждений отдельных молекул нуклеотидов. Найдено также, что при таком подходе появляется привлекательная возможность исследования динамики быстропротекающих колебательных процессов в биомакромолекулах.

\section{2. Экспериментальная часть}

Исследования спектров микрорамановского рассеяния света выполнены для оптимизированных полупроводниковых кристаллических квантовых точек $n c-\mathrm{Si} / \mathrm{SiO}_{2}$ с эффективным диаметром 4 нм. Такие наноструктуры функционализированы одноцепочными олигонуклеотидами $d(20 \mathrm{G}, 20 \mathrm{~T})$. Спектры микрорамановского рассеяния света самоорганизованных комплексов квантовых точек $n c-\mathrm{Si} / \mathrm{SiO}_{2}$ и олигонуклеотидов $d(20 \mathrm{G}, 20 \mathrm{~T})$ резонансно возбуждались излучением второй гармоники лазера на алюмоиттриевом гранате с длиной волны $\lambda_{i}=532$ нм по методике, приведенной в [8]. Спектральный состав рассеянного света анализировался с высокими спектральным и пространственным разрешениями с помощью спектрометра Horiba LabRAM HR800, (France) с охлаждаемой ПЗС (CCD) матрицей в качестве детектора. Спектральное разрешение составляло $2 \mathrm{~cm}^{-1}$ (0.25 мэВ). Излучение лазера мощностью 0.05 мВт фокусировалось на поверхность образца с использованием $100 \times$ микроскопного объектива (Olympus). Диаметр пятна лазерного излучения в фокусе составлял 0.9 мкм.

\section{3. Экспериментальные результаты и их обсуждение}

Спектры микрорамановского рассеяния света, обнаруженные в самоорганизованных комплексах кристаллических квантовых точек $n c-\mathrm{Si} / \mathrm{SiO}_{2}$ и олигонуклеотидов $d(20 \mathrm{G}, 20 \mathrm{~T})$ в диапазоне частот $600-1050 \mathrm{~cm}^{-1}$, приведены на рис. 1, и в расширенном диапазоне частот 850-1050 $\mathrm{cm}^{-1}$ (рис. 2) в квантовых точках $n c-\mathrm{Si} / \mathrm{SiO}_{2}$, функционализированных олигонуклеотидами $d(20 \mathrm{G}, 20 \mathrm{~T})$, спектр 1, а также в самих исходных олигонуклеотидах $d(20 \mathrm{G}, 20 \mathrm{~T})$, спектр 2 и на рис. 3 в олигонуклеотидах $d(20 \mathrm{G}, 20 \mathrm{~T})$.

Такие спектры получены при одинаковых экспериментальных условиях (температура, геометрия рассеяния, длина волны и плотность мощности возбуждающего излучения и т.п.). Из представленных спектров хорошо видно, что в процессе микрорамановского рассеяния света комплексов квантовых точек $n c-\mathrm{Si} / \mathrm{SiO}_{2}$, функционализированных олигонуклеотидами $d(20 \mathrm{G}, 20 \mathrm{~T})$, наблюдаются новые особенности, связанные с доминированием и существенным изменением спектров олигонуклеотидов.

Спектры олигонуклеотидов определяются пространственной структурой, задаваемой большим числом входящих в ее примитивную ячейку атомов, совершающих колебания относительно положений своего равновесия.

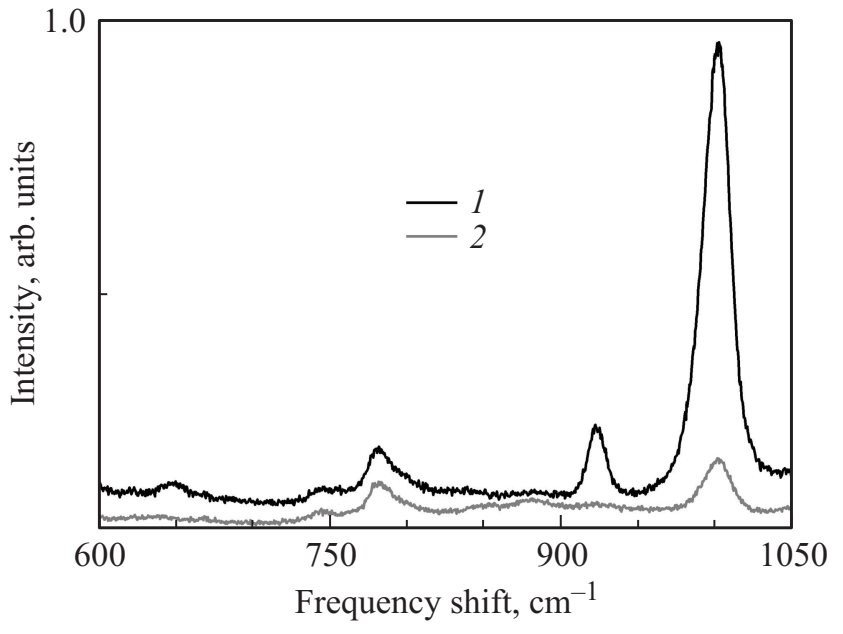

Рис. 1. Экспериментальные спектры микрорамановского рассеяния света в самоорганизованных комплексах кристаллических квантовых точек $n c-\mathrm{Si} / \mathrm{SiO}_{2}$ и олигонуклеотидов $d(20 \mathrm{G}, 20 \mathrm{~T})$ (спектр 1) и в самих олигонуклеотидах $d(20 \mathrm{G}, 20 \mathrm{~T})$ (спектр 2), обнаруженные в диапазоне частот $600-1450 \mathrm{~cm}^{-1}$. Спектры получены при комнатной температуре. Спектральное разрешение $2 \mathrm{~cm}^{-1}$.

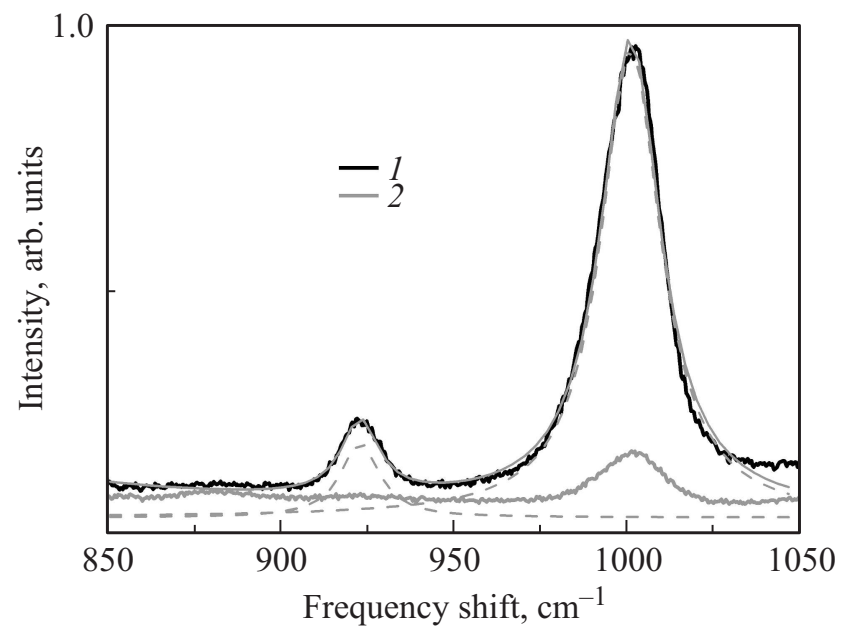

Рис. 2. Спектры микрорамановского рассеяния света в самоорганизованных комплексах кристаллических квантовых точек $n c-\mathrm{Si} / \mathrm{SiO}_{2}$ и олигонуклеотидов $d(20 \mathrm{G}, 20 \mathrm{~T}$ ) (спектр 1 ) и в самих олигонуклеотидах $d(20 \mathrm{G}, 20 \mathrm{~T})$ (спектр 2) в диапазоне частот 850-1050 $\mathrm{cm}^{-1}$. Узкая линия при $(1001.12 \pm 0.04) \mathrm{cm}^{-1}$ обусловлена фосфатной группой $\mathrm{PO}_{2}^{-}$сахарофосфатного остова. Пунктирные линии - лоренцевы контуры, выделенные из наблюдаемого контура Фойгта, полученные с учетом аппаратной функции, описываемой гауссовым контуром. Экспериментальные условия те же, что и для спектров, приведенных на рис. 1.

Макромолекулы коротких олигонуклеотидов, как и макромолекулы белков, не содержат ни центров инверсии, ни зеркальной симметрии. В целом структурное упорядочение биологических систем, и в частности олигонуклеотидов, является результатом низкой симметрии их 
Измеренные значения спектральных параметров частоты $v\left(\mathrm{~cm}^{-1}\right)$, ширины линии $\Gamma\left(\mathrm{cm}^{-1}\right)$ и площади под кривой $A$ (отн. ед.) для олигонуклеотидов $d(20 \mathrm{G}, 20 \mathrm{~T})$ и комплексов квантовых точек $n c-\mathrm{Si} / \mathrm{SiO}_{2}$, функционализированных олигонуклеотидами $d(20 \mathrm{G}, 20 \mathrm{~T})$

\begin{tabular}{c|c|c|c}
\hline Образцы & $v, \mathrm{~cm}^{-1}$ & $\Gamma, \mathrm{cm}^{-1}$ & $A$, отн. ед. \\
\hline$d(20 \mathrm{G}, 20 \mathrm{~T})$ & $1001.34 \pm 0.06$ & $20.67 \pm 0.29$ & $1940 \pm 20$ \\
$n c-\mathrm{Si} / \mathrm{SiO}_{2}+d(20 \mathrm{G}, 20 \mathrm{~T})$ & $1001.12 \pm 0.04$ & $20.97 \pm 0.15$ & $11620 \pm 84$
\end{tabular}

элементарных ячеек, обладающих винтовой или хиральной асимметрией $[14,15]$. В спектрах микрорамановского рассеяния света таких макромолекул должны наблюдаться сильно перекрывающиеся спектральные вклады, генерируемые большим набором атомов. Измеренные значения спектральных параметров частоты $v\left(\mathrm{~cm}^{-1}\right)$, ширины линии $\Gamma\left(\mathrm{cm}^{-1}\right)$ и площади под кривой $A$, (отн. ед.) для олигонуклеотидов $d(20 \mathrm{G}, 20 \mathrm{~T})$ и комплексов квантовых точек $n c-\mathrm{Si} / \mathrm{SiO}_{2}$, функционализированных олигонуклеотидами $d(20 \mathrm{G}, 20 \mathrm{~T})$, приведены в таблице.

Как видно из рис. 1-3 и таблицы, полученные экспериментальные результаты демонстрируют, что достигнутые высокие спектральное и пространственное разрешения, а также высокая чувствительность методики регистрации спектров комбинационного рассеяния света оказались достаточными для обнаружения достаточно узких линий и выделения спектральных составляющих, соответствующих колебаниям отдельных молекул [16-21]. При этом оказалось возможным и выявление изменений их относительных интенсивностей. Экспериментальные результаты демонстрируют существенное возрастания интенсивности спектральных линий отдельных одиночных молекул. При этом относительные интенсивности для таких отдельных линий различны и, следовательно,

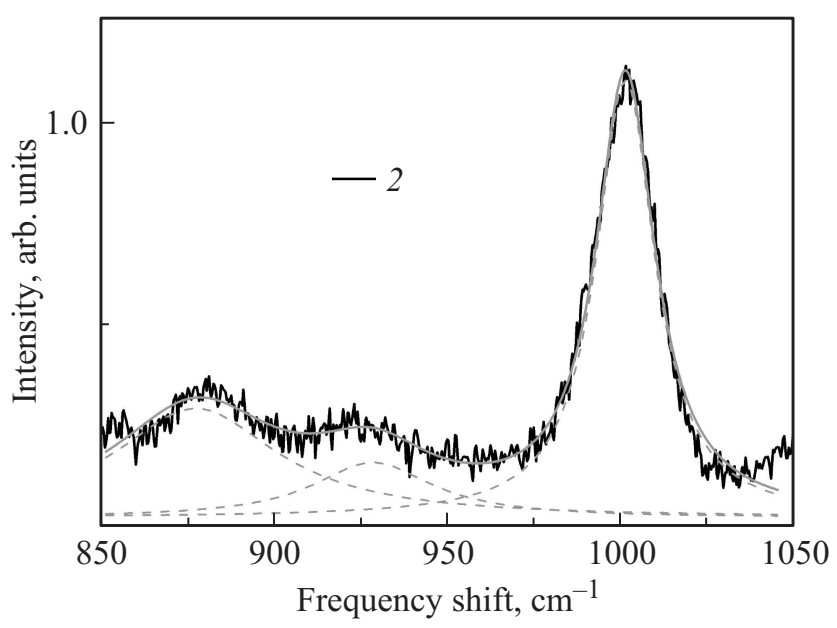

Pис. 3. Спектры микрорамановского рассеяния света в олигонуклеотидах $d(20 \mathrm{G}, 20 \mathrm{~T})$ (спектр 2) в диапазоне частот $850-1050 \mathrm{~cm}^{-1}$. Узкая линия при $(1001.34 \pm 0.06) \mathrm{cm}^{-1}$ обусловлена фосфатной группой $\mathrm{PO}_{2}^{-}$сахарофосфатного остова. Пунктирные линии - лоренцевы контуры, выделенные из наблюдаемого контура Фойгта, полученные с учетом аппаратной функции, описываемой гауссовым контуром. Экспериментальные условия те же, что и для спектров, приведенных на рис. 1. величины коэффициента усиления для них значительно отличаются. Обнаружение таких новых особенностей усиления интенсивности рассеяния в прямом сравнении со спектрами исходных олигонуклеотидов в широком спектральном диапазоне прямо указывает на многозонный резонансный характер процесса селективного усиления интенсивности рассеяния на отдельных молекулярных группах.

Отметим, что микроскопические механизмы такого многозонного резонансного рассеяния света существенно отличаются от традиционно исследуемого двухзонного резонансного усиления интенсивности комбинационного рассеяния света в полупроводниковых материалах (например, [22,23]). Физические основы такого явления многозонного резонансного усиления интенсивности рассеяния света впервые были теоретически предсказаны и экспериментально обнаружены в процессах рассеяния света Мандельштама-Бриллюэна акустическими фононами на примере кристаллов $\mathrm{ZnSe}[24,25]$. Впоследствии многозонное резонансное усиление интенсивности рассеяния света было обнаружено и для процесса комбинационного рассеяния света на оптических фононах на примере кристаллов $\mathrm{AgI}$ [26] и $\mathrm{GaP}$ [27]. Развитые подходы показали, что усиление возникает при резонансном поглощении фотонов с энергией, близкой к энергии рождения скоррелированных кулоновским взаимодействием электрон-дырочных пар. В этом случае в соответствующих выражениях для поперечного сечения рассеяния в качестве промежуточных электронных состояний были дополнительно рассмотрены водородоподобные экситонные состояния, принадлежащие как дискретным зонам, так и непрерывному спектру. Помимо этого, на основании подробного анализа измеренных значений зависимостей интенсивностей рассеяния света и поперечного сечения рассеяния от энергии квантов возбуждающего лазерного излучения в широком диапазоне энергий была обоснована и непосредственно установлена необходимость учета дополнительных каналов рассеяния. В результате в выражениях поперечного сечения рассеяния света для такого многозонного процесса рассеяния были включены в рассмотрение дополнительные вклады, описывающие участие еще и трех зон. А именно нижней зоны проводимости $\Gamma_{6}$, валентных зон легких и тяжелых дырок $\Gamma_{8}$, а также зоны $\Gamma_{7}$, отщепленной спин-орбитальным взаимодействием, с вовлечением всех возможных межзонных и внутризонных переходов. Развитые подходы многозонного резонансного рассеяния света [24-27] были непосредственно использованы в работе [20], а также для пересмотра ранее опублико- 
ванных авторами этой работы теоретических и экспериментальных результатов по исследованию резонансного рассеяния света акустическими и оптическим фононами в целом ряде полупроводников $\mathrm{A}^{\mathrm{II}} \mathrm{B}^{\mathrm{VI}}$ и $\mathrm{A}^{\mathrm{III}} \mathrm{B}^{\mathrm{V}}[20]$. $\mathrm{B}$ последующие годы теория многозонного резонансного рассеяния света и развитые подходы [24-27] были подтверждены для многих полупроводниковых материалов - от объемных (например, [7]) до низкоразмерных наноструктур, включая квантовые точки [8,28-43]. В низкоразмерных наноструктурах формирование большого числа экситонных уровней энергии обусловливает наиболее яркое проявление механизма многозонного резонансного неупругого рассеяния света. В комплексах квантовых точек $n c-\mathrm{Si} / \mathrm{SiO}_{2}$, функционализированных олигонуклеотидами $d(20 \mathrm{G}, 20 \mathrm{~T})$, в селективном процессе усиления интенсивности неупругого рассеяния света фотовозбужденный электрон в квантовой точке может в результате одноактного процесса безызлучательно, подобно тому, как это рассматривается в моделях Ферстера (Förster) [44] и Дехтера (Dexter) [45], перейти на уровень, образованный верхней занятой и нижней свободной молекулярными орбиталями олигонуклеотида $d(20 \mathrm{G}, 20 \mathrm{~T})$ с последующим резонансным рассеянием на колебательных уровнях различных молекулярных групп олигонуклеотида. Недавно подобный анализ процессов безызлучательного переноса энергии между двумя полупроводниковыми квантовыми точками на основе соединений $\mathrm{A}^{\mathrm{III}} \mathrm{B}^{\mathrm{V}}$ был сделан в работе [46]. Скорость переноса электрона для безызлучательного процесса сильно зависит от расстояния между квантовой точкой и центром донорно-акцепторной пары и определяет большой набор каналов рассеяния для колебаний отдельных молекулярных групп. Реализация в процессе безызлучательного резонансного переноса электрона, обладающего высокой чувствительностью к изменениям расстояния между донором и акцептором на нанометровой шкале, делает возможным наблюдение селективного усиления интенсивности при микрорамановском рассеянии света в комплексах биомолекул и квантовых точек. В результате появляется возможность экспериментально детектировать спектральные характеристики, обусловленные конформационными изменениями биомолекул.

Полученные результаты, как уже отмечалось выше, показывают, что одной из наиболее важных особенностей является также высокая воспроизводимость методики и обнаружение удивительно узких спектральных линий и в спектрах олигонуклеотидов $d(20 \mathrm{G}, 20 \mathrm{~T})$ [12-14], и в комплексах квантовых точек $n c-\mathrm{Si} / \mathrm{SiO}_{2}$, функционализированных олигонуклеотидами. Обнаруженные узкие линии, обусловленные рассеянием света одиночными молекулами олигонуклеотида, сохраняют свою ширину и в спектрах комплекса. Так, одна из наиболее узких линий с частотой $(1001.34 \pm 0.06) \mathrm{cm}^{-1}$, характерная для фосфатных групп $\mathrm{PO}_{2}^{-}$сахарофосфатного остова структуры олигонуклеотида, имеет одинаковое значение ширины линии и в спектрах олигонуклеотидов $d(20 \mathrm{G}, 20 \mathrm{~T})$ и в спектрах комплексов ПКТ $n c-\mathrm{Si} / \mathrm{SiO}_{2}$, функционали- зированных олигонуклеотидами. Непосредственное измерение естественной полуширины этой спектральной линии впервые дает возможность определить временной масштаб элементарных колебательных возбуждений в комплексах квантовых точек, функционализированных олигонуклеотидами. Полуширина линии (полная ширина на половине ее высоты) определяется как $\Gamma=1 / 2 \pi c \tau$, где $c-$ скорость света, и $\tau-$ время жизни возбуждения. Для измеренного значения полуширины с $\Gamma=(20.67 \pm 0.29) \mathrm{cm}^{-1}$ соответствующее время жизни для колебаний фосфатных групп $\mathrm{PO}_{2}^{-}$сахарофосфатного остова с учетом вкладов на ангармонические взаимодействия при комнатной температуре оказалось равным $(0.25 \pm 0.05)$ пс. Такое наблюдение, в частности, указывает на сохранение и в комплексах ПКТ $n c-\mathrm{Si} / \mathrm{SiO}_{2}$, функционализированных олигонуклеотидами, временно́го масштаба элементарных колебательных возбуждений, определенного для самих олигонуклеотидов $d(20 \mathrm{G}, 20 \mathrm{~T})$. Важным следствием наблюдения такой узкой спектральной линии в спектре комплексов ПКТ $n c-\mathrm{Si} / \mathrm{SiO}_{2}$, функционализированных олигонуклеотидами, является и то, что ее обнаружение прямо указывает на формирование устойчивой и стабильной пространственной молекулярной структуры синтезированных коротких одноцепочечных олигонуклеотидов длиной 40 нуклеотидов, последовательности $d(20 \mathrm{G}, 20 \mathrm{~T})$, а также сохранение этой структуры в лиофилизованном состоянии в комплексах ПКТ $n c-\mathrm{Si} / \mathrm{SiO}_{2}$, функционализированных олигонуклеотидами. Выводы об устойчивости, стабильности, а также о высоком совершенстве молекулярной структуры синтезированных комплексов ПКТ $n c-\mathrm{Si} / \mathrm{SiO}_{2}$, функционализированных одноцепочечными олигонуклеотидами $d(20 \mathrm{G}, 20 \mathrm{~T})$, также подтверждаются и другими спектральными особенностями. В частности, наличием и сохранением наиболее характерных максимумов, наблюдаемых во всем диапазоне частот на спектрах, представленных на рис. 1.

\section{4. Заключение}

На примере самоорганизованных комплексов и квантовых точек $n c-\mathrm{Si} / \mathrm{SiO}_{2}$, функционализированных олигонуклеотидами $d(20 \mathrm{G}, 20 \mathrm{~T})$, полученные экспериментальные данные с помощью спектроскопии микрорамановского рассеяния света высокого спектрального и пространственного разрешений в прямом сравнении со спектрами исходных олигонуклеотидов указывают на возможность обнаружения новых кантово-размерных эффектов, а именно резонансного селективного усиления интенсивности отдельных линий одиночных молекул ДНК в широком спектральном диапазоне рассеянного света. Обнаружение узких спектральных линий делает возможным экспериментальное исследование внутренних динамических свойств быстропротекающих процессов колебательных движений атомов в гибридных комплексах квантовых точек, функционализированных биомакромолекулами. Измерение величин естественной 
полуширины линий и/или времени жизни колебательных состояний отдельных молекул может также служить надежной мерой специфичности и степени совершенства молекулярной структуры таких комплексов с биомакромолекулами.

Работа выполнена при финансовой поддержке программ президиума РАН „Наноструктуры: физика, химия, биология, основы технологий“ и „Фундаментальные и прикладные проблемы фотоники и физика новых оптических материалов“, а также проекта „Granbis“ Агентства финансирования технологий и инноваций TEKES (Финляндия) и в рамках государственного задания Минобрнауки России 16.9790.2017/БЧ.

\section{Список литературы}

[1] M. Fujii, Y. Kanzawa, S. Hayashi, K. Yamamoto. Phys. Rev. B, 54, R8373 (1996).

[2] M.V. Wolkin, J. Jorne, P.M. Fauchet, G. Allan, C. Delerue, C. Phys. Rev. Lett., 82 (1), 197 (1999).

[3] K. Sato, K. Hirakuri. J. Appl. Phys., 100 (11), 11303 (2006).

[4] A.J. Nozik. Chem. Phys. Lett., 457 (1), 3 (2008).

[5] K. Dohnalová, A.N. Poddubny, A.A. Prokofiev, W.D.A.M. de Boer, C.P. Umesh, J.M.J. Paulusse, H. Zuilhof, T. Gregorkiewicz. Light: Sci. Appl., 2, e47 (2103).

[6] M.R. Bergren, P.K. Palomaki, N.R. Neale, T.E. Furtak, M.C. Beard. ACS Nano, 10 (2), 2316 (2016).

[7] F.H. Bayramov, G. Irmer, V.V. Toporov, B.H. Bairamov. Jpn. J. Appl. Phys., 50, 05FE06 (2011).

[8] Ф.Б. Байрамов, В.В. Топоров, Е.Д. Полоскин, Б.Х. Байрамов, C. Röder, C. Sprung, G. Bohmhammel, K. Seidel, G. Irmer, A. Lashkul, E. Lahderanta, Y.W. Song. ФTT, 47, 607 (2013).

[9] Н.Е. Маслова, А.А. Антоновский, Д.М. Жигунов, В.Ю. Тимошенко, В.Н. Глебов, В.Н. Семиногов. ФТП, 44, 1074 (2010).

[10] К.А. Гончар, Л.А. Головань, В.Ю. Тимошенко, В.А. Сиваков, С. Кристиансен. Изв. РАН. Сер. физ., 74, 1782 (2010).

[11] В.А. Володин, В.А. Сачков. ЖЭТФ, 143, 100 (2013).

[12] H. Marnix, M.H. Medema, R. Raaphorst, E. Takano, R. Breitling. Nat. Rev. Microbiol., 10, 191 (2012).

[13] В.Ю. Тимошенко, А.А. Кудрявцев, Л.А. Осминкина, А.С. Воронцов, Ю.В. Рябчиков, И.А. Белогорохов, Д. Ковалев, П.К. Кашкаров. Письма ЖЭТФ, 83, 492 (2008).

[14] Yu.E. Kitaev, A.G. Panfilov, V.P. Smirnov, P. Tronc. Phys. Rev. E, 67, 011907 (2003).

[15] G. Rosenman, P. Beker, I. Koren, M. Yevnin, B. Bank-Srour, E. Mishinab, S. Semin. J. Pept. Sci., 17, 75 (2011).

[16] Ф.Б. Байрамов, Е.Д. Полоскин, А.Л. Чернев, В.В. Топоров, M.В. Дубина, Е. Lahderanta, А. Lashkul, Н. Lipsanen, Б.Х. Байрамов. Письма ЖТФ, 40 (8), 44 (2014).

[17] Ф.Б. Байрамов, Е.Д. Полоскин, А.Л. Чернев, В.В. Топоров, M.В. Дубина, Е. Lahderanta, A. Lashkul, H. Lipsanen, Б.Х. Байрамов. ФТТ, 56 (6), 1224 (2014).

[18] Ф.Б. Байрамов, Е.Д. Полоскин, А.Л. Чернев, В.В. Топоров, М.В. Дубина, С. Sprung, Е. Lahderanta, A. Lashkul, Н. Lipsanen, Б.Х. Байрамов. ФТП, 48 (11), 1521 (2014).

[19] Ф.Б. Байрамов, Е.Д. Полоскин, А.А. Корнев, А.Л. Чернев, В.В. Топоров, М.В. Дубина, С. Roder, С. Sprung,
Н. Lipsanen, Б.Х. Байрамов. Письма ЖТФ, 40 (22), 105 (2014).

[20] Ф.Б. Байрамов, В.В. Топоров, Е.Д. Полоскин, Б.Х. Байрамов, М.В. Дубина, Е. Лахдеранта, Х. Липсанен, Б.Х. Байрамов. Письма ЖЭТФ, 99, 437 (2014).

[21] Б.Х. Байрамов. ФТТ, 56, 707 (2016).

[22] R. Loudon. Proc. Royal Soc. (London) A, 275, 218 (1963).

[23] Рассеяние света в твердых телах, под ред. М. Кардоны (М., Мир. 1979) с. 545.

[24] B.H. Bairamov, E. Karajamaki, R. Laiho, T. Levola, A.B. Gol'tsev, V.V. Toporov. Phys. Rev. B, 29, 4508 (1984).

[25] B.H. Bairamov, A.B. Gol'tsev, V.V. Toporov, R. Laiho, T. Levola. Phys. Rev. B, 33, 5875 (1986).

[26] Б.Х. Байрамов, Н.В. Личкова, А.В. Гольцев, В.Д. Тимофеев, В.В. Топоров. ФТТ, 29, 754 (1987). [Sov. Phys. Solid State, 29, 244 (1987)].

[27] Б.Х. Байрамов, А.В. Гольцев, В.В. Топоров, R.T. Phillips, Р. Лайхо, K. Dettmer. ФТТ, 40, 938 (1998). [Sov. Phys. Solid State, 40, 864 (1998)].

[28] A. Cantarero, C. Trallero-Giner, M. Cardona. Phys. Rev. B, 39, 8388 (1989).

[29] Y. Itoh, C. Hamaguchi. J. Phys. Soc. Jpn., 56 (6) 2192 (1987).

[30] B. Jusserand, M. Cardona. Raman spectroscopy of vibrations in superlattices. In: Light Scattering in Solids V (Springer, Berlin Heidelberg, 1989) p. 49.

[31] A. Koreeda, T. Nagano, S. Ohno, S. Saikan. Phys. Rev. B, 73 (2), 024303 (2006).

[32] C. Trallero-Giner, K. Syassen. Phys. Status Solidi B, 24 (7), 182 (2010).

[33] R.P. Miranda, M.I. Vasilevskiy, C. Trallero-Giner. Phys. Rev. B, 74, 115317 (2006).

[34] C. Trallero-Giner, K. Kunc, K. Syassen. Phys. Rev. B, 73, 205202 (2006).

[35] A.M. Yaremko, V.V. Koroteev, V.O. Yukhymchuk, V.M. Dzhagan, H. Ratajczak, A.J. Barnes, B. Silvi. Chem. Phys., 388, 57 (2011).

[36] A.N. Vamivakas, A. Walsh, Y. Yin, M.S. Ünlü, B.B. Goldberg, A.K. Swan. Phys. Rev. B, 74, 205405 (2006).

[37] K. Reimann, R.A. Kaindl, M. Woerner. Phys. Rev. B, 65, 045302 (2001).

[38] B.H. Bairamov, R.A. Evarestov, Yu.E. Kitaev, E. Jahne, M. Delaney, T.A. Gant, M.V. Klein, D. Levi, J. Klem, H. Morkoc. J. Phys. Chem., 95, 10772 (1991).

[39] L.G. Cançado, A. Jorio, M.A. Pimenta. Phys. Rev. B, 76, 064304 (2007).

[40] E. Menéndez-Proupin, C. Trallero-Giner, S.E. Ulloa. Phys. Rev. B, 60, 16747 (1999).

[41] Б.Х. Байрамов, В.В. Войтенко, Б.П. Захарченя, В.В. Топоров, М. Henini, А.J. Kent. Письма ЖЭТФ, 67, 972 (1998). [JETP Lett. 67, 428 (1998)].

[42] B. Jusserand, A.N. Poddubny, A.V. Poshakinskiy, A. Fainstein, A. Lemaitre. A. Phys. Rev. Lett., 115 (26), 267402 (2015).

[43] A. Kozorezov, J.K. Wigmore, A. Owens. J. Appl. Phys., 112 (5), 053709 (2012).

[44] Th. Förster. Ann. Phys., 2, 55 (1948).

[45] D.L. Dexter. J. Chem. Phys., 21, 836 (1953).

[46] О.П. Чикалова-Лузина, Д.М. Самосват, Г.Г. Зегря. Письма ЖТФ, 40, 64 (2014).

Редактор Г.А. Оганесян 


\section{Measurement of lifetimes of vibrational states of DNA molecules in functionalized complexes of semiconductor quantum dots}

F.B. Bayramov ${ }^{1,2}$, E.D. Poloskin ${ }^{2}$, A.L. Chernev ${ }^{1}$, V.V. Toporov' ${ }^{2}$, M.V. Dubina ${ }^{1}$, B.Kh. Bairamov ${ }^{2}$

${ }^{1}$ St. Petersburg Academic University,

Nanotechnology Research and Education Center, Russian Academy of Sciences,

194021 St. Petersburg, Russia

${ }^{2}$ loffe Institute,

194021 St. Petersburg, Russia

Abstract Complexes of the self-organized isolated semiconductor crystalline quantum dots of $n c-\mathrm{Si} / \mathrm{SiO}_{2}$, functionalized with short oligonucleotides are unique objects for revealing manifestation of new quantum-dimensional effects. It is shown that observation of narrow spectral lines in spectra of the high spectral resolution microraman light scattering allows to determine the characteristic time scale of times of vibrational excitations of molecules of nucleotides. It is set the possibility of quantitative study structural and fast dynamic properties of the vibrational processes in biomacromolecules and funded by Ministry of Education and Science of Russian Federation 16.9790.2017/Bch. 